\title{
MBLinhibitors.com, a Website Resource Offering Information and Expertise for the Continued Development of Metallo- $\beta$-Lactamase Inhibitors
}

\author{
Zishuo Cheng ${ }^{1}$, Caitlyn A. Thomas ${ }^{1}$, Adam R. Joyner ${ }^{2}$, Robert L. Kimble ${ }^{1}$, \\ Aidan M. Sturgill ${ }^{1}{ }^{\circledR}$, Nhu-Y Tran ${ }^{1}$, Maya R. Vulcan ${ }^{1}$, Spencer A. Klinsky ${ }^{1}$, Diego J. Orea ${ }^{1}$, \\ Cody R. Platt ${ }^{2}$, Fanpu Cao ${ }^{2}$, Bo Li ${ }^{2}$, Qilin Yang ${ }^{2}$, Cole J. Yurkiewicz ${ }^{1}$, Walter Fast ${ }^{3}$ and \\ Michael W. Crowder ${ }^{1, *} \mathbb{0}$ \\ 1 Department of Chemistry and Biochemistry, Miami University, Oxford, OH 45056, USA; \\ chengz5@miamioh.edu (Z.C.); thomas60@miamioh.edu (C.A.T.); kimblerl@miamioh.edu (R.L.K.); \\ sturgiam@miamioh.edu (A.M.S.); trann@miamioh.edu (N.-Y.T.); vulcanmr@miamioh.edu (M.R.V.); \\ klinsksa@miamioh.edu (S.A.K.); orea001@cougars.csusm.edu (D.J.O.); yurkiecj@miamioh.edu (C.J.Y.) \\ 2 Department of Computer Science and Software Engineering, Miami University, Oxford, OH 45056, USA; \\ joynerar@miamioh.edu (A.R.J.); plattcr@miamioh.edu (C.R.P.); caof2@miamioh.edu (F.C.); \\ lib6@miamioh.edu (B.L.); yangq11@miamioh.edu (Q.Y.) \\ 3 Division of Chemical Biology and Medicinal Chemistry, College of Pharmacy and the LaMontagne Center \\ for Infectious Disease, University of Texas, Austin, TX 78712, USA; walt.fast@austin.utexas.edu \\ * Correspondence: crowdemw@miamioh.edu; Tel.: +1-513-529-2813
}

Received: 17 February 2020; Accepted: 12 March 2020; Published: 16 March 2020

\begin{abstract}
In an effort to facilitate the discovery of new, improved inhibitors of the metallo- $\beta$-lactamases (MBLs), a new, interactive website called MBLinhibitors.com was developed. Despite considerable efforts from the science community, there are no clinical inhibitors of the MBLs, which are now produced by human pathogens. The website, MBLinhibitors.com, contains a searchable database of known MBL inhibitors, and inhibitors can be searched by chemical name, chemical formula, chemical structure, Simplified Molecular-Input Line-Entry System (SMILES) format, and by the MBL on which studies were conducted. The site will also highlight a "MBL Inhibitor of the Month", and researchers are invited to submit compounds for this feature. Importantly, MBLinhibitors.com was designed to encourage collaboration, and researchers are invited to submit their new compounds, using the "Submit" function on the site, as well as their expertise using the "Collaboration" function. The intention is for this site to be interactive, and the site will be improved in the future as researchers use the site and suggest improvements. It is hoped that MBLinhibitors.com will serve as the one-stop site for any important information on MBL inhibitors and will aid in the discovery of a clinically useful MBL inhibitor.
\end{abstract}

Keywords: antibiotic resistance; metallo- $\beta$-lactamase; website; inhibitor; mblinhibitor.com

\section{Introduction}

Antibiotic resistance is becoming an increasingly important biomedical issue, turning what was once easily treated with inexpensive and easily-accessible antibiotics into untreatable infections [1]. According to the Centers for Disease Control and Prevention (CDC), 2.8 million infections occur from antibiotic-resistant bacteria in the U.S. each year, with about 35,000 deaths from these infections [2]. The World Health Organization (WHO) predicts that over 10 million deaths, as well as an economic loss of $\$ 10$ trillion, will occur annually if effective intervention is not implemented [3]. Since the discovery of penicillin by Fleming in 1929, the $\beta$-lactam class remains the largest class of antibiotics for the treatment 
of bacterial infections, making up $65 \%$ of the antibacterial arsenal [4]. Penicillins, cephalosporins, carbapenems, and monobactams are all members of the $\beta$-lactam class [5]. The widespread use of this class of antibiotics has led to the emergence of different resistance mechanisms, including: (a) the production of altered penicillin binding proteins (PBP) with lower binding affinities for most $\beta$-lactam antibiotics; and (b) the production of $\beta$-lactamases, which is the most common resistance mechanism in Gram-negative bacteria [6]. In 2019, there are more than 2800 identified $\beta$-lactamase genes [7]. They have been classified biochemically into two categories according to the mechanism by which they hydrolyze the $\beta$-lactam bond [8]. The serine- $\beta$-lactamases (SBL) utilize an active site serine to hydrolyze the $\beta$-lactam bond. The metallo- $\beta$-lactamases (MBL) utilize $\mathrm{Zn}$ (II)-containing active sites to hydrolyze the $\beta$-lactam bond in these antibiotics [9].

Although the SBLs are more prevalent in the clinic over the past seventy years, there exist inhibitors, which can be given in combination with other $\beta$-lactam containing antibiotics, to treat bacteria that produce some of the SBLs [10]. Examples of these FDA-approved inhibitors include clavulanic acid, sulbactam, avibactam, and tazobactam [10]. However, despite considerable efforts to develop such inhibitors [6], there are no clinically-approved inhibitors that are available for MBLs, making infections from bacteria that produce MBL a serious challenge. An ideal MBL inhibitor would have good inhibition properties, low toxicity, and is broad-spectrum [11]. Three major challenges have limited success in preparing a clinical inhibitor of the MBLs. Firstly, there are large structural variances exhibited by the MBLs, even those from the same molecular subclass [12]. There are three subclasses of MBLs; B1, B2, and B3, and members are distinguished by amino acid sequence, molecular properties, identity of $\mathrm{Zn}$ (II)-coordinating ligands, and the number of active site metal ions present [9]. Across these subclasses, there is less than $20 \%$ amino acid sequence identities [13]. In the B1 subclass alone, there is only a modest $30 \%$ amino acid sequence similarities, with only a few highly-conserved residues present outside the $\mathrm{Zn}$ (II)-binding site [12]. This structural diversity has resulted in MBL inhibitors that inhibit only one (or a few) MBL, but not others. For example, the dicarboxylic acid compound ME1071 was reported to be a good inhibitor of MBL IMiPenemase (IMP-1) and VIM-2 Verona Integron-borne MBL (VIM-2) [14]. However, this compound is a poor inhibitor of subclass B1 MBL NDM-1 New Delhi MBL (NDM)-1) [15]. Another example is the bicyclic boronate VNRX-5133, which exhibits good inhibition against NDM and other subclass B1 enzymes [16]; however, this compound is not a good inhibitor of subclass B3 MBL L1 [16]. Secondly, it is imperative that any clinical MBL inhibitor be selective towards bacterial MBLs over human MBL-fold containing enzymes, some of which have important physiological roles [6]. The most common (and perhaps most obvious) way to inhibit an MBL is through the use of a chelating agent that binds to the $\mathrm{Zn}(\mathrm{II})$ ion(s) in the active site [17]. One can envision two limiting inhibition mechanisms used by such inhibitors: (1) stripping of the $\mathrm{Zn}$ (II) from the active site; or (2) coordination of the $\mathrm{Zn}$ (II) ion(s) while they are bound to the MBL to produce a ternary complex [17]. Many inhibitors that have metal binding scaffolds exhibit good in vitro inhibition properties [17], and one natural product, aspergillomarasmine (AMA), was reported to be effective in an in vivo infection model [18]. However, subsequent studies revealed unacceptable toxicities ( $50 \%$ lethal dose [ $\left.\mathrm{LD}_{50}\right]$ in mice is $159.8 \mathrm{mg} / \mathrm{kg}$ ), which limited its further development [19]. This study and others have suggested that metal-targeting inhibitors will need to be developed that form ternary complexes [17]. Thirdly, the continued emergence of new MBL variants exceeds the rate at which new inhibitors are currently being developed. The IMP-type MBLs were identified first in the late 1980s [20], while the VIM-type MLBs were first discovered in 1995 [21]. NDM-1 was first detected in 2008 [22]. There are currently 29, 69, and 85 clinical variants of NDM, VIM, and IMP listed in the $\beta$-lactamase database, respectively [23], and the number of clinical variants will continue to grow (Figure 1A). There is growing evidence that MBL inhibitors interact differently with different variants [24,25]. For example, one isoquinoline derivative potently inhibited VIM-5 and VIM-38, while the same compound was not nearly as potent toward VIM-1, VIM-2, or VIM-4 [26]. 
A
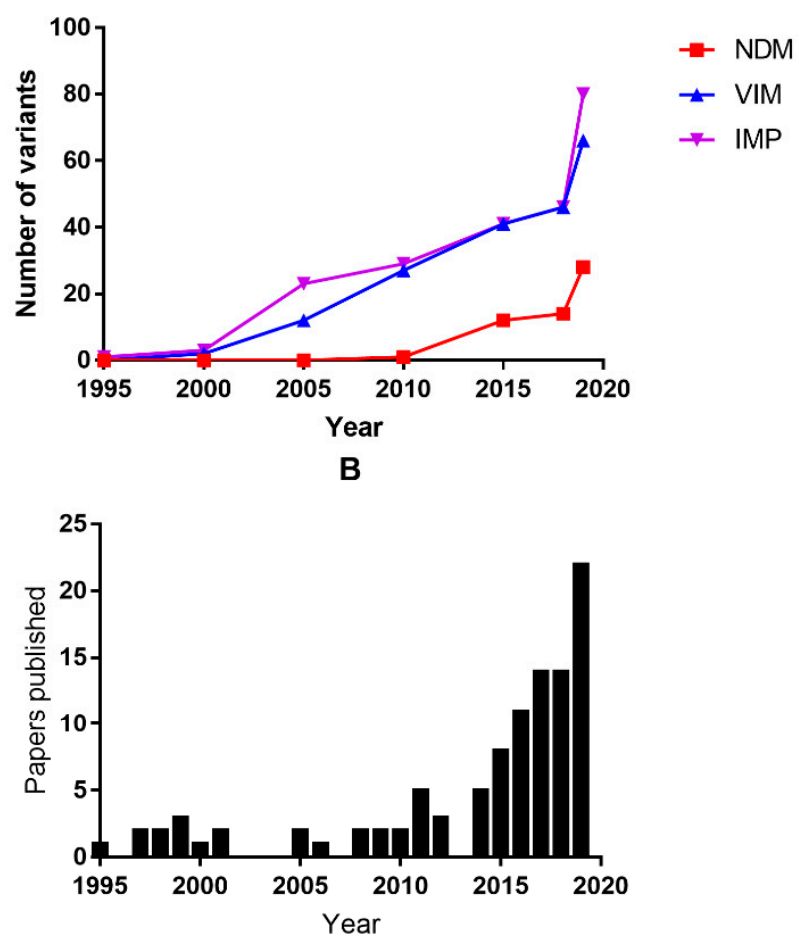

C

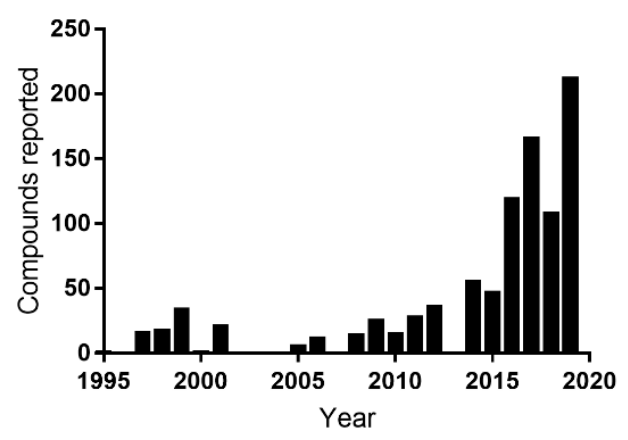

Figure 1. Increase in metallo- $\beta$-lactamases (MBL) and MBL inhibitors. (A) Selective MBL enumerated according to http://bldb.eu/. (B) Number of publications related to MBL inhibitors from year 1995 to 2019. (C) Number of reported MBL inhibitor from year 1995 to 2019.

In the past five years, there has been significant effort to identify novel inhibitors of the MBL [6,11]. The numbers of MBL inhibitors and publications describing MBL inhibitors have increased over the last decade (Figures 1B and 1C). The four major approaches to identify MBL inhibitors include: (1) high-throughput screening (HTS) of large chemical libraries [18]; (2) fragment-based drug discovery (FBDD) [27,28]; (3) computer-based virtual screening [29,30]; and (4) screening of natural products [31]. The typical "hit" rates of these approaches are very low $(<1 \%)$ [32]. Despite the low success rates, over 900 inhibitors have been reported in literature as of October 2019. Given this number of compounds, there have been several review articles that have categorized the inhibitors based on structure $[33,34]$ or mechanism of inhibition [12,17]. While these articles provide excellent insights to existing MBL inhibitors, and often suggest future directions, most review articles focus on the best inhibitors and do not often discuss compounds with relatively poor inhibition properties, even though these latter compounds may be great scaffolds for redesign efforts. In addition, review articles are typically not up to date, and some of them are published in journals that are difficult to access. With the increasing 
number of compounds (Figure 1C), it is becoming more difficult to collect and sort through the review articles or the original articles, which are not interactive or searchable.

To address these issues, we have developed a website called MBLinhibitors.com (link: https: //MBLinhibitors.miamioh.edu), which is the first effort, to our knowledge, to provide a searchable database of current and future MBL inhibitors. The primary goal of the website is to provide up-to-date information on MBL inhibitors to facilitate current and future MBL inhibitor development and/or redesign efforts. The initial form of MBLinhibitors.com includes structures of the MBL inhibitors, SMILES formats, toxicity results if available, mechanism of inhibition if known, $\mathrm{IC}_{50}$ values if reported, targeted enzymes, and primary references. It is hoped that additional information will be included as researchers start to use the website and offer suggestions and data to improve the site. The site has been designed for researchers to add their new inhibitors, and we hope that researchers will submit compounds with great promise, but also compounds that are not as promising at this time. The information about these latter compounds might prevent researchers from testing compounds that have already been shown to be poor MBL inhibitors, and ultimately save time and money to work on more promising candidates. The overarching hope is that providing up-to-date information in a concise, organized manner, and more importantly in one location, will facilitate more rapid development of future MBL inhibitors, and discovery of clinically useful compounds.

\section{Materials and Methods}

\subsection{Data Collection}

Literature searches (Keywords include metallo-beta-lactamase and inhibitor) were conducted using PubMed [35] and Google Scholar [36]. Articles reporting MBL inhibitors were selected manually. The structures of compounds were obtained from the literature and drawn using ChemDraw Version 18.1 (PerkinElmer, Waltham, MA, USA) In vitro inhibition ( $\mathrm{K}_{\mathrm{i}}$ and $\mathrm{IC}_{50}$ values), in vivo (minimum inhibitory concentration (MIC)), toxicity, inhibition, and crystal structural data were obtained from the articles. SMILES formats, molecular weights, and molecular formulas were determined using ChemDraw. All data were compiled in Microsoft Excel spreadsheets and converted into a comma-separated values (CSV) file.

\subsection{Website Construction}

In order to minimize running costs and retain ease of maintenance, a LAMP (Linux, Apache, MySQL, and Personal Home Page (PHP) stack was used to design the site. For development, PHP version 7.2 (Zend Technologies, Cupertino, CA, USA) and MySQL version 8.0.18 (Oracle, Redwood City, CA, USA) were used. The website was developed using Visual Studio Code, developed by Microsoft (Redmond, WA, USA). For the front-end, a framework called 'Materialize' was used in order to design a clean, uniform interface. All SMILES format drawings were dynamically drawn using a JavaScript library (Oracle, Redwood City, CA, USA) named 'SmilesDrawer' that was developed by Daniel Probst and Jean-Louis Reymond [37] (Berne, Switzerland). Any database calls were made by making HTTP requests to an internal PHP Application Programming Interface (API). The API parsed the incoming GET and POST requests and was able to connect to the MySQL database using the MySQLi class. The API could be exposed in the future to enable others to use this website's data in their own applications.

\section{Results}

The home page of the website includes a short video by Michael Crowder, which describes the website and the rationale for developing MBLinhibitors.com (Figure 2). The home page also includes a short feature called the "MBL Inhibitor of the Month." For the launch of the website, the developers chose to highlight recent work from Professor Chris Schofield's group at the University of Oxford (Oxford, UK) regarding his bicyclic boronate (VNRX-5133, Venatorx Pharmaceuticals, Malvern, PA, 
USA) inhibitor [16]. Professor Schofield and coworkers wrote a short perspective of the compound, and it is the intent to highlight new compounds each month. We will invite researchers to submit their compounds and descriptions of the compounds.
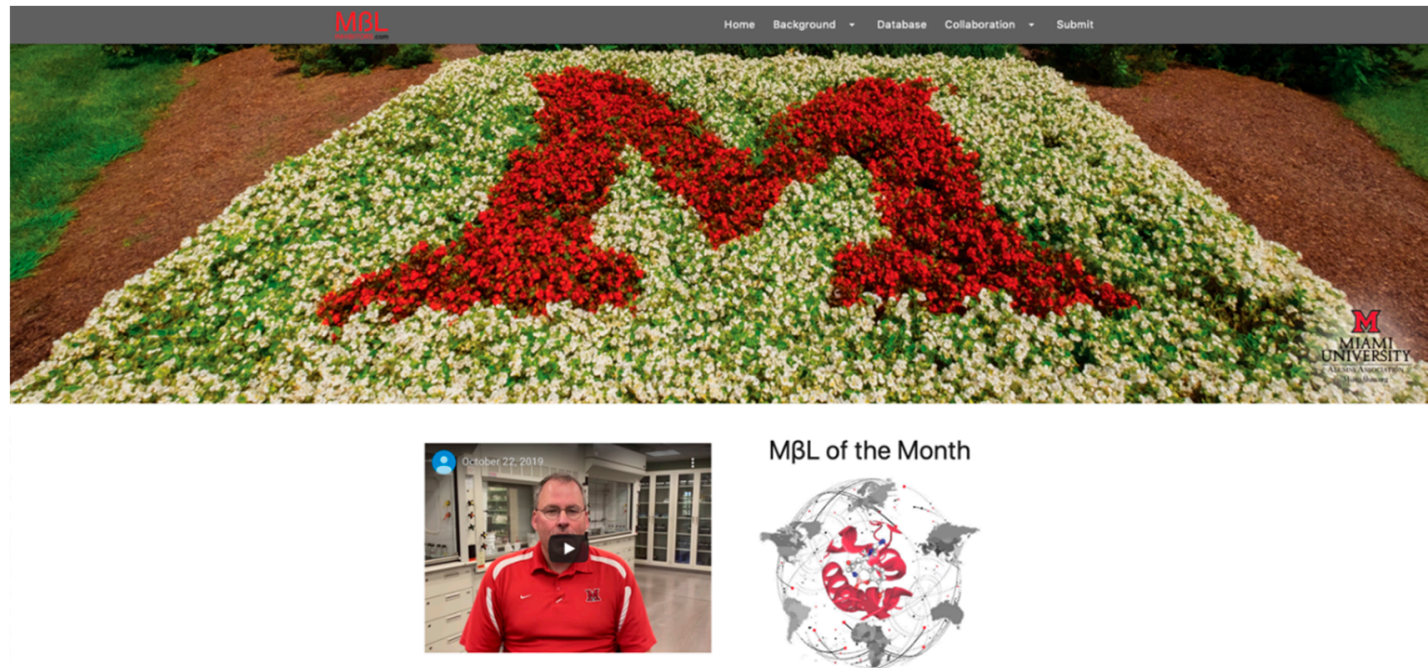

Figure 2. The home page of MBLinhibitor.com, which includes the main buttons, a short introductory video, and a short feature called the "MBL Inhibitor of the Month.

The home page also contains four menus (Figure 2), in addition to a home button. These menus are:

- "Background": This menu leads to information about the various MBLs and MBL inhibitors included within the website.

- "Database": This menu contains two functions; "Keyword Searching" and "Functional Group Filter." The former allows visitors to search for a specific MBL inhibitor by chemical name, chemical formula, chemical structure, and/or SMILES format (Figure 3). The latter allows visitors to narrow their search results based on one or more functional groups that make up the inhibitor. Researchers can also search by specific MBL, by simply the name of the enzyme (NDM, VIM, etc.). Once a search has been completed, a list of the inhibitors, with the name and chemical formula, is shown (Figure 3). By clicking on the "View" button, the researcher can access a structure of the compound, name, SMILES, molecular weight, testing data (if known), and a link to a relevant publication.

- "Collaboration": This menu currently contains a link to a description of Michael Crowder's research lab, email address, link to website, and a description of techniques conducted in the lab on MBL inhibitors. To encourage collaboration in the MBL community, a second link is an invitation to other researchers to join the list of collaborators, with a fillable form to provide information. Researchers can elect to submit information that will be posted on MBLinhibitors.com.

- "Submit": This function allows for researchers to submit new compounds to the database. Researchers can submit the chemical name, SMILES format (after this information is submitted, a structure is automatically drawn in the window), chemical formula, molecular weight, and publication information. After submission, the compound information will be reviewed and added to the mblinhibitor.com database. 


\begin{tabular}{|c|c|c|c|}
\hline $\bar{F}$ & Functional Groups & & \\
\hline \multicolumn{4}{|c|}{ SEARCH } \\
\hline Number & Name & Formula & Link \\
\hline 1 & "N-(2-chlorophenyl)-2-((5-(2-hydroxyphenyl)-4H-1,2,4-triazol-3-yl)thio)acetamide" & $\mathrm{C} 16 \mathrm{H} 13 \mathrm{CIN} 4 \mathrm{O} 2 \mathrm{~S}$ & VIEW \\
\hline 2 & "N-(3-chlorophenyl)-2-((5-(2-hydroxyphenyl)-4H-1,2,4-triazol-3-yl)thio)acetamide" & $\mathrm{C} 16 \mathrm{H} 13 \mathrm{CIN} 4 \mathrm{O} 2 \mathrm{~S}$ & VIEW \\
\hline 3 & "N-(4-chlorophenyl)-2-((5-(2-hydroxyphenyl)-4H-1,2,4-triazol-3-yl)thio)acetamide" & $\mathrm{C} 16 \mathrm{H} 13 \mathrm{CIN} 4 \mathrm{O} 2 \mathrm{~S}$ & VIEW \\
\hline 367 & "N-(2-chlorophenyl)-2-((5-(2-hydroxyphenyl)-4H-1,2,4-triazol-3-yl)thio)acetamide" & $\mathrm{C} 16 \mathrm{H} 13 \mathrm{CIN} 4 \mathrm{O} 2 \mathrm{~S}$ & VIEW \\
\hline 368 & "N-(2-chlorophenyl)-2-((5-(4-hydroxyphenyl)-4H-1,2,4-triazol-3-yl)thio)acetamide" & $\mathrm{C} 16 \mathrm{H} 13 \mathrm{CIN} 4 \mathrm{O} 2 \mathrm{~S}$ & VIEW \\
\hline 371 & "N-(3-chlorophenyl)-2-((5-(2-hydroxyphenyl)-4H-1,2,4-triazol-3-yl)thio)acetamide" & $\mathrm{C} 16 \mathrm{H} 13 \mathrm{CIN} 4 \mathrm{O} 2 \mathrm{~S}$ & VIEW \\
\hline 372 & "N-(3-chlorophenyl)-2-((5-(4-hydroxyphenyl)-4H-1,2,4-triazol-3-yl)thio)acetamide" & $\mathrm{C} 16 \mathrm{H} 13 \mathrm{CIN} 4 \mathrm{O} 2 \mathrm{~S}$ & VIEW \\
\hline
\end{tabular}

Figure 3. The demo of formula searching, using $\mathrm{C} 16 \mathrm{H} 13 \mathrm{ClN} 4 \mathrm{O} 2 \mathrm{~S}$ as the keyword. More detailed info can be obtained by clicking the "VIEW" button for each compound.

\section{Discussion}

\subsection{Data Sharing}

On this website, visitors have access to information on nearly 1000 different compounds, and compounds can be searched using the Inhibitor Database tab by chemical name, chemical formula, chemical structure, SMILES format, or by using the functional group filter. More detailed information about compounds in the database can be obtained by clicking the PubMed ID link associated with the compound. When developing this database, we chose information on the MBL inhibitors that we believed to be most useful to other research groups; however, we encourage researchers to contact us (using the Contact link on the Home page) about including additional data in the database. Our group will continue to conduct literature searches to find newly-reported MBL inhibitors or new inhibition/toxicity/in vivo/structural data on previously-reported compounds. However, researchers will be encouraged to submit their new compounds and data directly to the website, using the submit function under the "Submit" menu. The new compounds would include both compounds that are good inhibitors, and not good inhibitors. As we discussed in the Introduction section, the success rate for identifying new inhibitors from screening large chemical compounds is only $1 \%$, and the success rate for modified scaffolds is $12 \%-80 \%$ [32]. Therefore, there is a lot of unreported information in these screens that could be used to guide future structure/activity efforts. We hope that this website will be a repository of all MBL inhibitor discovery efforts, including the large portion that is now invisible to the MBL community.

In addition, we believe the information in this website has great potential in the future for in silico analyses. Drug discovery is resource-intensive, and it is estimated to cost drug makers $\$ 2.6$ billion and 10-20 years to develop new prescription medicines [38]. Artificial intelligence (AI) may be used to accelerate this process, and reduce costs by more quickly identifying promising leads [39]. Even though no MBL inhibitors have been discovered by using machine learning so far, this approach has 
been used to identify inhibitors of other biomedically-important enzymes [40,41]. Each compound in our database includes its SMILES format, which is commonly used in in silico analyses.

\subsection{Expertise Sharing}

Based on literature searches and analyses of resulting data that we compiled on 930 compounds, $100 \%$ of the compounds have some steady state inhibition data, $36 \%$ have reported MIC data, $5 \%$ have reported mechanisms of inhibition, $12 \%$ have toxicity data, and $4 \%$ have crystal structures with MBL inhibitor(s) complexed to a MBL. Even though a goal of most MBL inhibitor discovery efforts is finding a pan inhibitor, only $22 \%$ of the compounds were tested against MBLs from multiple subclasses, and only one of the 930 compounds was tested against variants of a single MBL. Given the number of current compounds with missing data, the increase in number of new compounds being reported, and the increase in number of clinical variants [23], it will be necessary for researchers to share expertise and work together to fill the information void. We hope that MBL researchers will be willing to post their names and contact information on the site, and details about their research programs; interested researchers should contact the Crowder group.

\section{Conclusions}

In this paper, we describe a new, interactive website called MBLinhibitors.com. We believe it is an open-access, one-stop solution for the developers of MBL inhibitors, to get the most up-to-date information and to facilitate the formation of collaborations.

Author Contributions: Conceptualization: Z.C.; data curation: R.L.K., A.M.S., N.-Y.T., M.R.V., S.A.K., D.J.O., C.J.Y.; validation: C.A.T.; software: A.R.J., C.R.P., F.C., B.L., Q.Y.; writing-original draft preparation: Z.C.; writing-review and editing: W.F., M.W.C. All authors have read and agreed to the published version of the manuscript.

Funding: This research was funded by National Institutes of Health, under grants R01 GM111926 (to W.F., M.W.C., R.A.B., D.L.T., and R.C.P.) and R15 GM134454 (to M.W.C.). D.J.O. was supported by an NSF-REU grant (CHE-1851795).

Acknowledgments: The authors would like to thank Alen Krajnc and Christopher Schofield for providing the information for the inaugural "MBL Inhibitor of the Month" for the site.

Conflicts of Interest: The authors declare no conflicts of interest.

\section{References}

1. Fair, R.J.; Tor, Y. Antibiotics and bacterial resistance in the 21st century. Perspect. Med. Chem. 2014, 6, 25-64. [CrossRef] [PubMed]

2. 2019 AR Threats Report. Available online: https://www.cdc.gov/drugresistance/biggest-threats.html (accessed on 13 March 2020).

3. No Time to Wait: Securing the Future from Drug-Resistant Infections. Available online: https://www.who. int/antimicrobial-resistance/interagency-coordination-group/final-report/en/ (accessed on 13 March 2020).

4. Chandel, A.K.; Rao, L.V.; Narasu, M.L.; Singh, O.V. The realm of penicillin G acylase in $\beta$-lactam antibiotics. Enzyme Microb. Technol. 2008, 42, 199-207. [CrossRef]

5. $\quad$ Bush, K.; Bradford, P.A. $\beta$-Lactams and $\beta$-Lactamase Inhibitors: An Overview. Cold Spring Harb. Perspect. Med. 2016, 6. [CrossRef] [PubMed]

6. Tooke, C.L.; Hinchliffe, P.; Bragginton, E.C.; Colenso, C.K.; Hirvonen, V.H.A.; Takebayashi, Y.; Spencer, J. $\beta$-Lactamases and $\beta$-Lactamase Inhibitors in the 21st Century. J. Mol. Biol. 2019, 431, 3472-3500. [CrossRef]

7. Bush, K. Past and Present Perspectives on $\beta$-Lactamases. Antimicrob. Agents Chemother. 2018, 62, e01076-18. [CrossRef]

8. Bonomo, R.A. $\beta$-Lactamases: A Focus on Current Challenges. Cold Spring Harb. Perspect. Med. $2017,7$. [CrossRef]

9. Mojica, M.F.; Bonomo, R.A.; Fast, W. B1-Metallo- $\beta$-Lactamases: Where Do We Stand? Curr. Drug Targets 2016, 17, 1029-1050. [CrossRef] 
10. Papp-Wallace, K.M.; Bonomo, R.A. New $\beta$-Lactamase Inhibitors in the Clinic. Infect Dis. Clin. N. Am. 2016, 30, 441-464. [CrossRef]

11. Shi, C.; Chen, J.; Kang, X.; Shen, X.; Lao, X.; Zheng, H. Approaches for the discovery of metallo- $\beta$-lactamase inhibitors: A review. Chem. Biol. Drug Des. 2019, 94, 1427-1440. [CrossRef]

12. Rotondo, C.M.; Wright, G.D. Inhibitors of metallo- $\beta$-lactamases. Curr. Opin. Microbiol. 2017, 39, 96-105. [CrossRef]

13. Karsisiotis, A.I.; Damblon, C.F.; Roberts, G.C. A variety of roles for versatile zinc in metallo- $\beta$-lactamases. Metallomics 2014, 6, 1181-1197. [CrossRef] [PubMed]

14. Ishii, Y.; Eto, M.; Mano, Y.; Tateda, K.; Yamaguchi, K. In vitro potentiation of carbapenems with ME1071, a novel metallo- $\beta$-lactamase inhibitor, against metallo- $\beta$-lactamase- producing Pseudomonas aeruginosa clinical isolates. Antimicrob. Agents Chemother. 2010, 54, 3625-3629. [CrossRef] [PubMed]

15. Livermore, D.M.; Mushtaq, S.; Morinaka, A.; Ida, T.; Maebashi, K.; Hope, R. Activity of carbapenems with ME1071 (disodium 2,3-diethylmaleate) against Enterobacteriaceae and Acinetobacter spp. with carbapenemases, including NDM enzymes. J. Antimicrob. Chemother 2012, 68, 153-158. [CrossRef] [PubMed]

16. Krajnc, A.; Brem, J.; Hinchliffe, P.; Calvopiña, K.; Panduwawala, T.D.; Lang, P.A.; Kamps, J.J.A.G.; Tyrrell, J.M.; Widlake, E.; Saward, B.G.; et al. Bicyclic Boronate VNRX-5133 Inhibits Metallo- and Serine- $\beta$-Lactamases. J. Med. Chem. 2019, 62, 8544-8556. [CrossRef]

17. Ju, L.C.; Cheng, Z.; Fast, W.; Bonomo, R.A.; Crowder, M.W. The Continuing Challenge of Metallo- $\beta$-Lactamase Inhibition: Mechanism Matters. Trends Pharmacol. Sci. 2018, 39, 635-647. [CrossRef] [PubMed]

18. King, A.M.; Reid-Yu, S.A.; Wang, W.; King, D.T.; De Pascale, G.; Strynadka, N.C.; Walsh, T.R.; Coombes, B.K.; Wright, G.D. Aspergillomarasmine A overcomes metallo- $\beta$-lactamase antibiotic resistance. Nature 2014, 510, 503-506. [CrossRef] [PubMed]

19. Bergstrom, A.; Katko, A.; Adkins, Z.; Hill, J.; Cheng, Z.; Burnett, M.; Yang, H.; Aitha, M.; Mehaffey, M.R.; Brodbelt, J.S.; et al. Probing the Interaction of Aspergillomarasmine A with Metallo- $\beta$-lactamases NDM-1, VIM-2, and IMP-7. ACS Infect. Dis. 2018, 4, 135-145. [CrossRef]

20. Watanabe, M.; Iyobe, S.; Inoue, M.; Mitsuhashi, S. Transferable imipenem resistance in Pseudomonas aeruginosa. Antimicrob. Agents Chemother. 1991, 35, 147-151. [CrossRef]

21. Lauretti, L.; Riccio, M.L.; Mazzariol, A.; Cornaglia, G.; Amicosante, G.; Fontana, R.; Rossolini, G.M. Cloning and characterization of bla(VIM), a new integron-borne metallo- $\beta$-lactamase gene from a Pseudomonas aeruginosa clinical isolate. Antimicrob. Agents Chemother. 1999, 43, 1584-1590. [CrossRef]

22. Yong, D.; Toleman, M.A.; Giske, C.G.; Cho, H.S.; Sundman, K.; Lee, K.; Walsh, T.R. Characterization of a New Metallo- $\beta$-Lactamase Gene, blaNDM-1, and a Novel Erythromycin Esterase Gene Carried on a Unique Genetic Structure in Klebsiella pneumoniae Sequence Type 14 from India. Antimicrob. Agents Chemother. 2009, 53, 5046-5054. [CrossRef]

23. Naas, T.; Oueslati, S.; Bonnin, R.A.; Dabos, M.L.; Zavala, A.; Dortet, L.; Retailleau, P.; Iorga, B.I. Beta-lactamase database (BLDB)-structure and function. J. Enzyme Inhib. Med. Chem. 2017, 32, 917-919. [CrossRef] [PubMed]

24. Cheng, Z.; Thomas, P.W.; Ju, L.; Bergstrom, A.; Mason, K.; Clayton, D.; Miller, C.; Bethel, C.R.; VanPelt, J.; Tierney, D.L.; et al. Evolution of New Delhi metallo- $\beta$-lactamase (NDM) in the clinic: Effects of NDM mutations on stability, zinc affinity, and mono-zinc activity. J. Chem. Biol. 2018, 293, 12606-12618. [CrossRef] [PubMed]

25. LaCuran, A.E.; Pegg, K.M.; Liu, E.M.; Bethel, C.R.; Ai, N.; Welsh, W.J.; Bonomo, R.A.; Oelschlaeger, P. Elucidating the Role of Residue 67 in IMP-Type Metallo- $\beta$-Lactamase Evolution. Antimicrob. Agents Chemother. 2015, 59, 7299-7307. [CrossRef] [PubMed]

26. Makena, A.; Düzgün, A.Ö.; Brem, J.; McDonough, M.A.; Rydzik, A.M.; Abboud, M.I.; Saral, A.; Çiçek, A.Ç.; Sandalli, C.; Schofield, C.J. Comparison of Verona Integron-Borne Metallo- $\beta$-Lactamase (VIM) Variants Reveals Differences in Stability and Inhibition Profiles. Antimicrob. Agents Chemother. 2015, 60, 1377-1384. [CrossRef] [PubMed]

27. Chen, A.Y.; Thomas, P.W.; Stewart, A.C.; Bergstrom, A.; Cheng, Z.; Miller, C.; Bethel, C.R.; Marshall, S.H.; Credille, C.V.; Riley, C.L.; et al. Dipicolinic Acid Derivatives as Inhibitors of New Delhi Metallo- $\beta$-lactamase-1. J. Med. Chem. 2017, 60, 7267-7283. [CrossRef]

28. Chen, A.Y.; Thomas, P.W.; Cheng, Z.; Xu, N.Y.; Tierney, D.L.; Crowder, M.W.; Fast, W.; Cohen, S.M. Investigation of Dipicolinic Acid Isosteres for the Inhibition of Metallo- $\beta$-Lactamases. Chem. Med. Chem. 2019, 14, 1271-1282. [CrossRef] 
29. Kang, J.S.; Zhang, A.L.; Faheem, M.; Zhang, C.J.; Ai, N.; Buynak, J.D.; Welsh, W.J.; Oelschlaeger, P. Virtual Screening and Experimental Testing of B1 Metallo- $\beta$-lactamase Inhibitors. J. Chem. Inf. Model 2018, 58, 1902-1914. [CrossRef]

30. Brindisi, M.; Brogi, S.; Giovani, S.; Gemma, S.; Lamponi, S.; De Luca, F.; Novellino, E.; Campiani, G.; Docquier, J.-D.; Butini, S. Targeting clinically-relevant metallo- $\beta$-lactamases: From high-throughput docking to broad-spectrum inhibitors. J. Enzyme Inhib. Med. Chem. 2016, 31, 98-109. [CrossRef]

31. Shi, C.; Chen, J.; Xiao, B.; Kang, X.; Lao, X.; Zheng, H. Discovery of NDM-1 inhibitors from natural products. J. Glob. Antimicrob. Resist. 2019, 18, 80-87. [CrossRef]

32. Truchon, J.F.; Bayly, C.I. Evaluating virtual screening methods: Good and bad metrics for the "early recognition" problem. J. Chem. Inf. Model 2007, 47, 488-508. [CrossRef]

33. Fast, W.; Sutton, L.D. Metallo- $\beta$-lactamase: Inhibitors and reporter substrates. Biochim. Biophys. Acta Proteins Proteom. 2013, 1834, 1648-1659. [CrossRef] [PubMed]

34. González, M.M.; Vila, A.J. An Elusive Task: A Clinically Useful Inhibitor of Metallo- $\beta$-Lactamases. In Zinc Enzyme Inhibitors: Enzymes from Microorganisms; Supuran, C.T., Capasso, C., Eds.; Springer International Publishing: Cham, Switzerland, 2017; pp. 1-34.

35. PubMed. Available online: https://www.ncbi.nlm.nih.gov/pubmed/ (accessed on 13 March 2020).

36. Google Scholar. Available online: https://scholar.google.com/ (accessed on 13 March 2020).

37. Probst, D.; Reymond, J.L. SmilesDrawer: Parsing and Drawing SMILES-Encoded Molecular Structures Using Client-Side JavaScript. J. Chem. Inf. Model 2018, 58, 1-7. [CrossRef] [PubMed]

38. DiMasi, J.A.; Grabowski, H.G.; Hansen, R.W. Innovation in the pharmaceutical industry: New estimates of R\&D costs. J. Health Econ. 2016, 47, 20-33. [CrossRef] [PubMed]

39. Smalley, E. AI-powered drug discovery captures pharma interest. Nat. Biotechnol. 2017, 35, 604-605. [CrossRef]

40. Jamal, S.; Grover, A.; Grover, S. Machine Learning From Molecular Dynamics Trajectories to Predict Caspase-8 Inhibitors Against Alzheimer's Disease. Front. Pharmacol. 2019, 10. [CrossRef] [PubMed]

41. Zhavoronkov, A.; Ivanenkov, Y.A.; Aliper, A.; Veselov, M.S.; Aladinskiy, V.A.; Aladinskaya, A.V.; Terentiev, V.A.; Polykovskiy, D.A.; Kuznetsov, M.D.; Asadulaev, A.; et al. Deep learning enables rapid identification of potent DDR1 kinase inhibitors. Nat. Biotechnol. 2019, 37, 1038-1040. [CrossRef]

(C) 2020 by the authors. Licensee MDPI, Basel, Switzerland. This article is an open access article distributed under the terms and conditions of the Creative Commons Attribution (CC BY) license (http://creativecommons.org/licenses/by/4.0/). 